\title{
Variability of summer precipitation over Eastern China during the last millennium
}

\author{
C. Shen ${ }^{1}$, W.-C. Wang ${ }^{1}$, Y. Peng ${ }^{2,3}$, Y. Xu ${ }^{3}$, and J. Zheng ${ }^{4}$ \\ ${ }^{1}$ Atmospheric Sciences Research Center, State University of New York, Albany, New York, USA \\ ${ }^{2}$ Key Laboratory of Western China's Environmental Systems, Lanzhou University, Lanzhou, China \\ ${ }^{3}$ Laboratory for Climate Studies, China Meteorological Administration, Beijing, China \\ ${ }^{4}$ Institute of Geographical Sciences and Natural Resources Research, Chinese Academy of Sciences, Beijing, China
}

Received: 2 April 2008 - Published in Clim. Past Discuss.: 22 May 2008

Revised: 31 March 2009 - Accepted: 31 March 2009 - Published: 6 April 2009

\begin{abstract}
We use measurements of recent decades, 1500-yr proxy data, and millennium model simulations with a variety of climate facings to study the temporal and spatial variability of summer precipitation over eastern China. Spectral analysis of the proxy data using multi-taper method reveals three statistically significant bidecadal (15-35-yr), pendadecadal (40-60-yr), and centennial (65-170-yr) oscillation bands. The results of wavelet filtering show that the amplitudes of these bands vary substantially through time depending on the temperature regimes. Weak centennial oscillation and strong pentadecadal oscillation occur in warm conditions, whereas both the centennial and pentadecadal oscillations are strong in cold conditions. A model/data intercomparison suggests that pentadecadal and bidecadal oscillations could be associated with internal variability of the climate system. It is also found that the increased frequency of drought-in-north/flood-in-south spatial pattern over eastern China during the last two decades is unusual in the past five centuries.
\end{abstract}

\section{Introduction}

The Earth's climate has significantly warmed in the last few decades, most likely due to anthropogenic forcing (Folland et al., 2001; Jones et al., 2001; Hegerl et al., 2007). In order to assess the impacts of climate change under global warming on the human societies and natural ecosystems and to develop suitable adaptation and mitigation policies, a better understanding of climate variability under "natural" and

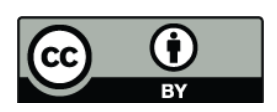

Correspondence to: $\mathrm{C}$. Shen (cshen@climate.cestm.albany.edu) "anthropogenic" conditions and accurate climate change predictions are needed at the global and, more importantly, the regional and local scales (Bradley et al., 2003; Jones and Mann, 2004; Giorgi, 2005). Changes in globally average climate are primarily determined by the radiative budget of the coupled atmosphere-ocean-land system and modulated by internal non-linear feedbacks (Stocker et al., 2001; Giorgi, 2005). A positive global radiative forcing such as greenhouse effect generally causes global warming and an increase of global precipitation as a consequence of increased evaporation from the warmer land and ocean surfaces (Allen and Ingram, 2003). However, climates, especially precipitation, are primarily controlled by circulation regimes and modes of internal modes of variability at the regional scale. For example, the Asian monsoon and its interactions with the El Nino/Southern Oscillation (ENSO) and extratropical circulations are the major sources of interannual variability of summer precipitation over Asia (Wang, 2006). Therefore, the study of variability in seasonal precipitation on the regional scale is vital to providing detailed picture we need in our research for an unambiguous "fingerprint" of the climate response to increasing greenhouse gas emissions (Barnett et al., 1999; Jones et al., 2001).

Eastern China is located in the monsoonal Asia, which is vulnerable to small changes in the timing and intensity of monsoon precipitation. The vulnerability is likely to increase in the future with continued population growth and intensified land-use (Feddema et al., 2005; Zhao et al., 2006; Pielke et al., 2007). The monsoon system is highly variable over a broad range of timescales from days to millennia. We have come to know a great deal about Asian monsoon dynamics on seasonal to interannual time scales due to an increased wealth of new data from satellite observations

Published by Copernicus Publications on behalf of the European Geosciences Union. 
and field experiments, and the advances in computing power and mathematical representations of coupled climate system (Wang, 2006). For example, It has been known that the ENSO event and Quasi-biennial Oscillation (QBO) have been the primary source of the precipitation over East Asia on seasonal to interannual time scales (Ding, 1991; Waliser, 2006; Yang and Luo, 2006). It is also known that astronomical variations in seasonal insolation have been the primary pacemaker of the Asian monsoon on glacial-interglacial time scales (e.g. Clemens et al., 2003; Wang et al., 2005), and solar activities have been hypothesized as the driver of a 1500yr cycle in Holocene monsoon dynamics (e.g. Gupta et al., 2005; Wang et al., 2005). However, the patterns and causes of decadal-centennial variability are not well understood due to the limits in the length of observational records and relatively coarse resolution of proxy data. Although work to date has revealed many strong hints of decadal to quasicentennial oscillations in the summer precipitation over eastern China using relatively short observational data and proxy data (e.g. Zhu and Wang, 2002; Ding et al., 2007), the behavior of decadal to centennial variability in time and space is still unclear in the context of millennia. In this study, we analyze the $1500-y r$ proxy data of summer precipitation to examine long-term variability with a focus on decadal to centennial oscillations.

Some studies using observational and modeled data have indicated an increase in the frequency of drought-innorth/flood-in-south over eastern China during the last few decades (Xu, 2001; Ding et al., 2007). It has been ascribed to the response of summer precipitation to anthropologic forcing (Xu, 2001; Menon et al., 2002; Fu, 2003). However, question is how unusual this variability of summer precipitation in the last few decades in the millennium context of climate. The last millennium is an epoch including Medieval Warm Period (AD 800-1100 in China, Yang et al., 2002) with climate as warm as the last century. It also encompasses the period before large-scale contamination of the global atmosphere by human activities and globalscale changes in land-surface condition (Bradley et al., 2003; Jones and Mann, 2004). Therefore, the study of the variability in summer precipitation over eastern China during the time interval longer than observational record is essential for assessing the temporal and spatial variability of summer precipitation under "natural" and "anthropogenic" condition and for understanding the role of anthropogenic forcing in future precipitation variations. In this study, we analyze observational, proxy, and modeled data to examine the occurrence probability of different spatial patterns over eastern China during the instrumental and historical times.

Theoretical models of the climate system driven with external forcing can provide important insights into the factors governing climate changes in the past (Jones and Mann, 2004). Simulations of climate changes over the last millennium have been performed using energy balance models (EBMs, e.g. Crowley, 2000), two-dimensional climate mod- els (e.g. Bauer et al., 2003), and general circulation models (GCMs, e.g. Ammann et al., 2007). However, studies of model/data intercomparison mainly focused on temperature. There has been little attempt to test climate models with precipitation proxy data or interpret such proxy data using model simulations (Yoshimori et al., 2006). In this study, the millennium simulations driven with natural and anthropogenic focrcing and fixed forcing (control run) using Community Climate System Model (CCSM, version 2.0.1) are used to analyze the variability of summer precipitation over eastern China during the last millennium. The comparisons of modeled, observed, and proxy data are conducted to assess the performance of CCSM2.0.1 in simulating the spatial patterns and temporal variability of summer precipitation over eastern China, and to provide some potential insights into the factors influencing temporal and spatial variability of summer precipitation over eastern China during the last millennium.

\section{Data and methods}

The data used in this study include observational, modeled, and proxy data of summer precipitation (May-September) over eastern China (Table 1). Observational precipitation data we analyze are from the Beijing Climate Center (BCC) and the Climate Research Unit of the University of East Anglia. The former is a data set of precipitation from 1951 to 2000 at 160 stations over China, and the latter is a data set of land-only precipitation in a $3.75^{\circ} \times 2.5^{\circ}$ resolution covering a period of 1901-2000. Proxy data used in this study is a dataset of the dryness/wetness index (DWI), a proxy data of summer rainfall, over eastern China from 1470 to 2000, derived from Chinese historical documents and instrumental measurements (CNMA, 1981; Zhang et al., 2003). Additionally, two 1500-yr time series of regional DWI covering two regions, i.e. North China (NC, $\left.34-41^{\circ} \mathrm{N}, 107-120^{\circ} \mathrm{E}\right)$ and the middle-lower Yangtze River Valley (MLYRV, $26-34^{\circ} \mathrm{N}$, $109-122^{\circ} \mathrm{E}$ ) over eastern China (Zheng et al., 2006) are also analyzed. This dataset is also derived from Chinese historical documents.

Model data are three millennium simulations of CCSM2.0.1 developed by the National Center for Atmospheric Research (NCAR; Kiehl and Gent 2004). The model comprises four components of the climate system: the atmosphere, ocean, land surface, and sea ice. These components are linked via a flux coupler without flux corrections. The atmospheric component is a primitive equation model with T31 in horizontal resolution $\left(\sim 3.75^{\circ}\right.$ in latitude and longitude) and 26 hybrid-coordinate levels in the vertical. The land component has the same horizontal grid as the atmosphere and includes 5 different surface types (glacier, lake, wetland, urban, and vegetated) with 4 to 16 different vegetation types. The ocean component is the NCAR implementation of POP (Parallel Ocean Program) 
Table 1. Observed, modeled, and proxy data of summer precipitation over eastern China.

\begin{tabular}{lllll}
\hline Data Sets & Spatial resolution & Temporal resolution & Length & Reference \\
\hline BCC_dataset & point & Monthly & $1951-2000$ & http://bcc.cma.gov.cn \\
UK CRU Land Surface & $3.75 \times 2.5$ & Monthly & $1850-2000$ & Hulme, 1992, 1994 \\
D/W index & Point & Seasonal & $1570-2000$ & CNMA, 1981 \\
Regional D/W index & Area & Seasonal & $505-1995$ & Zheng et al., 2006 \\
NCAR-CCSM 2.0.1 & T31L26 & monthly & $1000-1999$ & This study \\
\hline
\end{tabular}

and has a longitudinal resolution of $\sim 3.6^{\circ}$ and variable latitudinal resolutions of $\sim 1.8^{\circ}$ and up to $\sim 0.9^{\circ}$ in the Tropics. The sea-ice component is a dynamic-thermodynamic model with same horizontal grid as the ocean component. Three simulations including a control run, a run with orbital and solar forcing, and another run with full forcing are conducted. Forcing time series used in runs include the global and seasonal change of the orbital insolation (Berger, 1978), the solar variation and volcanic eruption (Crowley et al., 2003), and the greenhouse gases (Ammann et al., 2007).

In this study, principal components analysis (PCA) is employed to reveal the spatial patterns of summer precipitation over eastern China. Multi-taper method (MTM) (Ghil et al., 2002) and wavelet analysis (Torrence and Campo, 1998) are applied to detect decadal to centennial oscillations of summer precipitation and their temporal evolution during the pat 1500 years over eastern China.

\section{Results and discussion}

\subsection{Variability of summer precipitation in observational data}

Eastern China is located in the East Asian monsoon region. The summer monsoon brings about $70 \%$ of the total annual precipitation to this region. On average, the summer monsoon onset occurs in early to mid-May when heavy convective rainfall develops over southern China along the preMeiyu front. It is then followed by abrupt northward shifts of the summer monsoon, causing an elongated rain belt referred to as Meiyu or "Plum Rains", a regional rainy season in June and July over the Yangtze River Valley in eastern China. The summer monsoon then shifts to northern China in July, triggering the rainy seasons of northern China. At the end of August, the summer monsoon begins to withdraw southward (Ding, 1991; Samel et al., 1999; Chang et al., 2000). Following this summer monsoon northward penetration, the summer precipitation over eastern China exhibits a significant gradient from south to north.

Beijing Climate Center has developed a dataset of monthly temperature and precipitation from 1951 to the present. It consists of 160 stations, covering the most land areas of China. Here we selected a subset of summer precipitation consisting 80 stations over eastern China to conduct PCA.
North et al. (1982) test were applied to determine whether the PCs are separable. Results (Fig. 1) show that the first four PCs can be separated according to North et al. (1982)'s rule of thumb. The first three PCs explain $18.3 \%, 13.7$, and $8.4 \%$ of the total variance in this dataset. PC1 indicates a threebelt mode of spatial pattern, in which NC and southeastern coast (SEC) have negative or little loading, and the MLYRV has high positive loading. PC2 reveals a dipole mode of spatial pattern. Positive loading occurs in the region north to $28^{\circ} \mathrm{N}$, whereas its south has negative PC loading. The third PC also shows a three-belt mode of spatial pattern. When the MLYRV has negative loading, NC and SEC has positive loading. It is evident that the result of PCA shows a distinct difference of summer precipitation variability in $\mathrm{NC}$ and the MLYRV during the past 50 years. Therefore, we choose NC and the MLYRV as our study regions to explore the tempospatial variability of summer precipitation during the instrumental and historical times over eastern China. Another reason why we choose them as our study regions is that $1500-y r$ proxy data of summer precipitation is available only in these two regions (Zheng et al., 2006).

During the last century, large interannual variability in summer precipitation is observed in both regions (Fig. 2a, b). In the MLYRV, average monthly summer precipitation varied from $110 \mathrm{~mm}$ (1900) to $230 \mathrm{~mm}$ (more than 2 standard deviation, 1958), while it varied from $55 \mathrm{~mm}$ (1900) to $113 \mathrm{~mm}$ (1964) in NC. Spectral analysis of these two time series reveals some significant cycles. 2-yr and 3-yr cycles are significant at the $95 \%$ confidence level in the MLYRV and NC (Fig. 3c), respectively. A number of studies have indicated that the interannual variability in summer precipitation over the Asian monsoon region is associated with the tropospheric biennial oscillation (TBO, Shen and Lau, 1995; Webster et al., 1998; Yang, and Lau, 2006), ENSO events (Wang et al., 2000, 2003; Lau and Wu, 2001), and snow cover over the Tibetan Plateau (Wu and Qian, 2003; Yang and Lau, 2006). 2-3-yr cycle revealed by summer precipitation in the MLYRV and NC is typical TBO and ENSO. Decadal variability in summer precipitation is not significant at the $95 \%$ confidence level in both the MLYRV and NC. Wavelet filtering of the time series shows that decadalcentennial band oscillations only explain $19.4 \%$ and $18.3 \%$ variance of summer precipitation in the MLYRV and NC, respectively. 

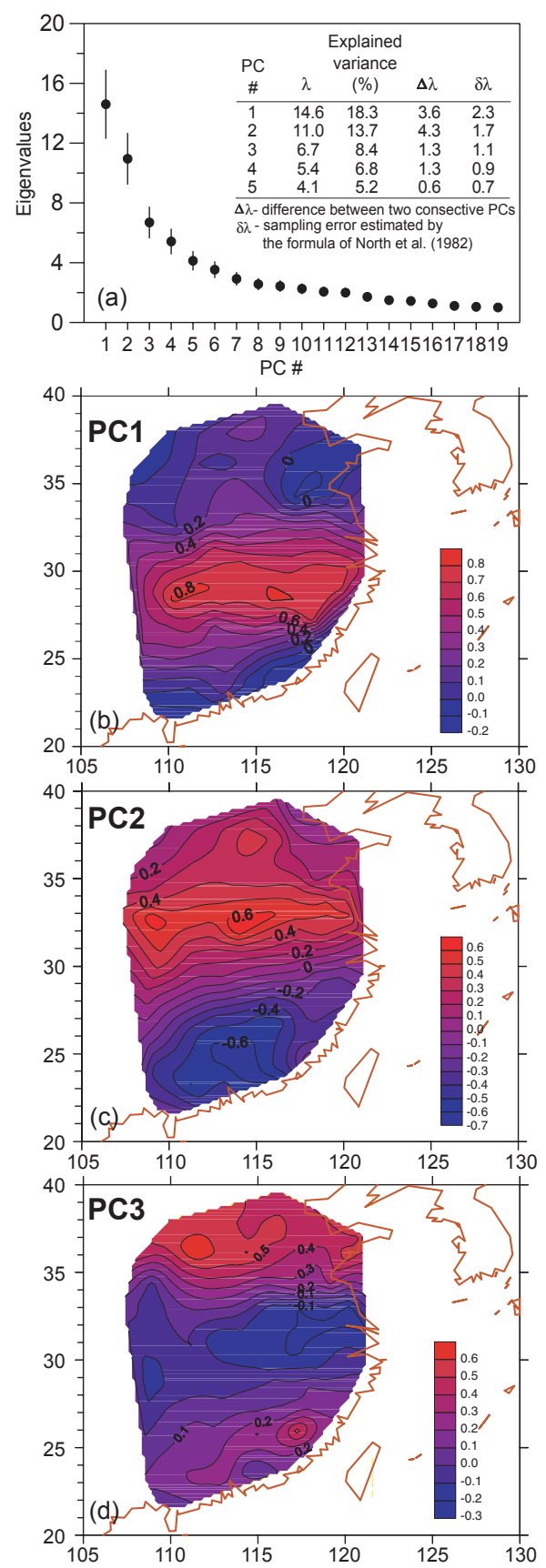

Fig. 1. Result of PCA on the observed data from 1951 to 2000 consisting of 80 stations over eastern China, including eigenvalue scree plot (a), and spatial patterns of loading in the first three PCs (b-c).

\subsection{Variability of summer precipitation in proxy data}

Proxy data of summer precipitation used here are DWI derived from the Chinese historical documents. This proxy data covers the past 1500 years. Due to that 10 -yr moving average was involved in developing regional DFI for the MLYRV

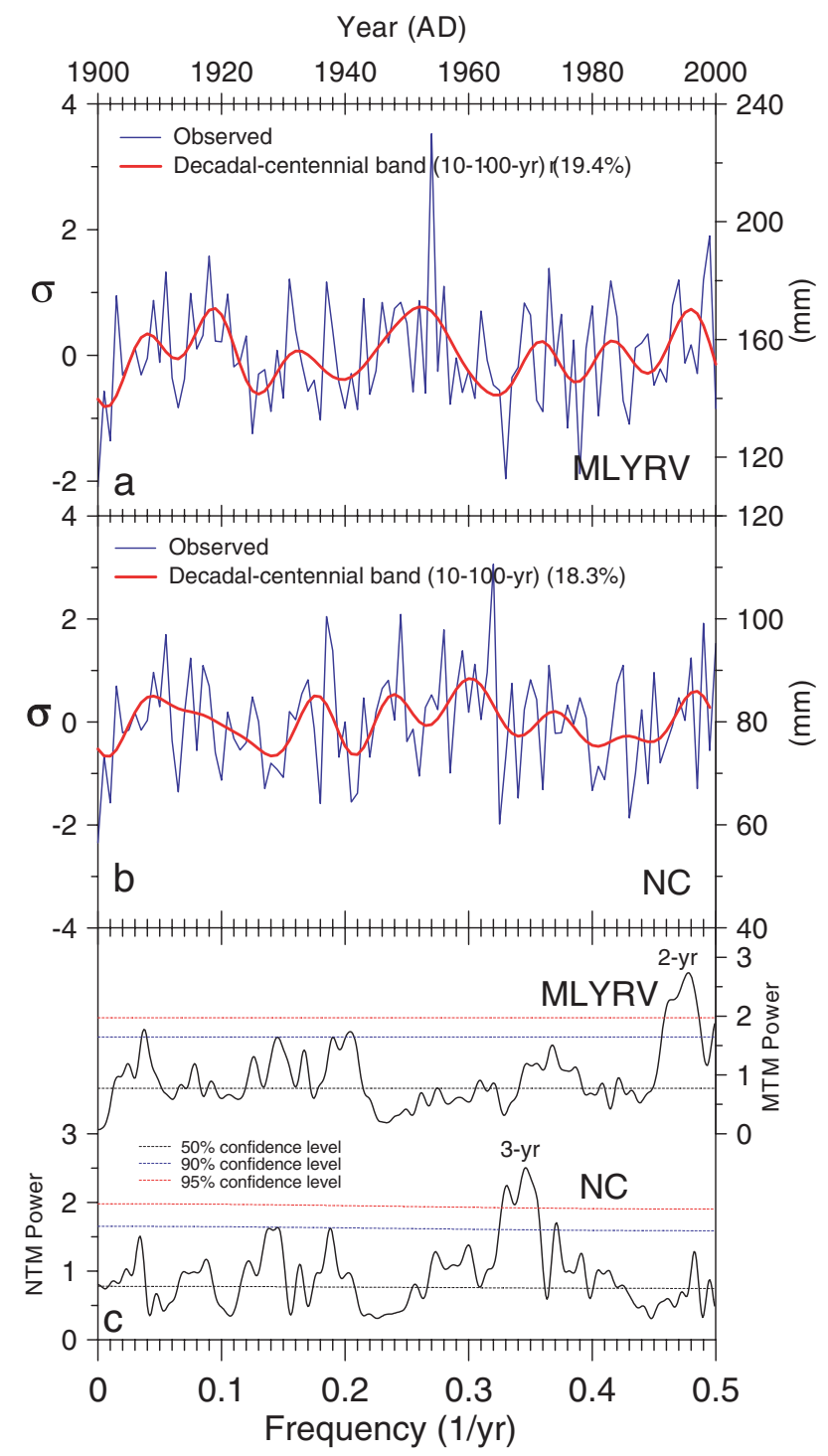

Fig. 2. (a) Observed summer precipitation in the MLYRV and its Wavelet filtered ( $T_{\text {pass }}=10-100-y r$, paul basis) time series. (b) Observed summer precipitation in $\mathrm{NC}$ and its Wavelet filtered ( $T_{\text {pass }}=10-100-\mathrm{yr}$, paul basis) time series. (c) MTM results of the MLYRV and NC summer precipitation time series. Resolution and taper number used in the MTM analysis are 2 and 3, respectively; red noise null hypothesis is selected; and a robust estimate of the red noise background is calculated using the approach of Mann and Lee (1996), and its confidence levels are shown.

and $\mathrm{NC}$, high frequency variability in the regional DWI time series was removed (Zheng et al., 2006). Therefore, they are used to examine decadal to centennial variability. Figure $3 \mathrm{a}$ and $\mathrm{b}$ show the normalized time series of DWI for the MLYRV and NC. To detect significant decadal to centennial variability, we conducted the MTM analysis on the two time series. In the MTM analysis, red noise null hypothesis is selected, i.e., the first-order autoregressive noise process 


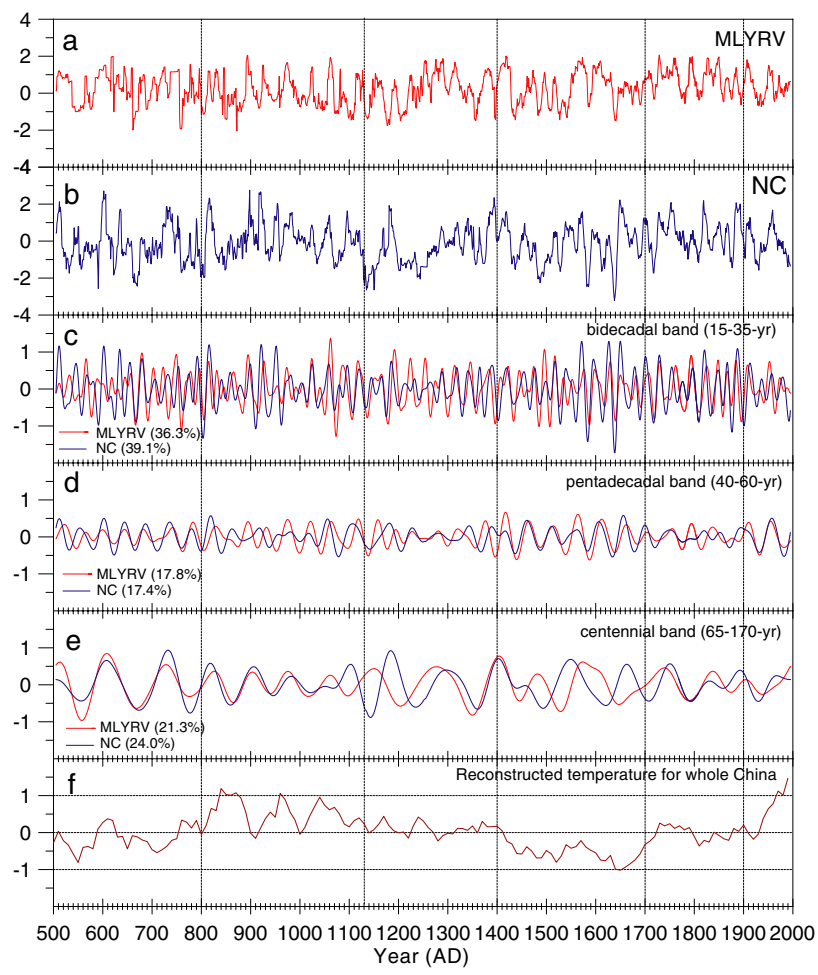

Fig. 3. The normalized time series of 10-yr moving averages of DWI for the MLYRV (a) and NC (b). Wavelet filtered DWI time series for the MLYRV and NC in bidecadal band $\left(T_{\text {pass }}=15-35-\mathrm{yr}\right.$, paul basis) (c), pentadecadal band ( $T_{\text {pass }}=40-60-$ yr, paul basis) $(\mathbf{d})$, and centennial band ( $T_{\text {pass }}=65-170-y r$, paul basis). A curve of reconstructed temperature for whole China (Yang et al., 2004) is also shown for a comparison of summer precipitation variability over eastern China with temperature variation in China.

is assumed because of high autocorrelation of proxy data. A robust estimate of the red noise background is calculated using the approach of Mann and Lee (1996). As shown by Fig. 4, decadal to centennial periodicities are well presented in both time series. For the MLYRV, the centennial-scale variation is dominated by the $100-110-y r$ and $120-170-y r$ oscillations, which are significant at the $95 \%$ confidence level. A peak stands up at 78-95-yr at the $90 \%$ confidence level. The major mode of multidecadal oscillation is 43-52-yr periodicity with more than $99 \%$ confidence level. Bidecadal oscillation consists of five oscillation modes, i.e. 15-17-yr, 18-19-yr, 21-23-yr, 26-28-yr, and 30-33-yr periodicities. Theses modes exceed the 95\% confidence level. Additionally, a quadridecadal oscillation (36-39-yr) with more than 99\% confidence level is also seen in the MLYRV time series. For NC, the centennial-scale oscillation consists of two cyclical modes at the 95\% confidence level, including 68$76-y r$ and $86-130-y r$ variations. A peak of $43-48$-yr exhibits at the $95 \%$ confidence level. Significant periodicities at the bidecadal oscillation are 17-19-yr, 20-29-yr, and 31-35-yr, in which the most prominent cyclic mode is $20-29-$ yr vari-

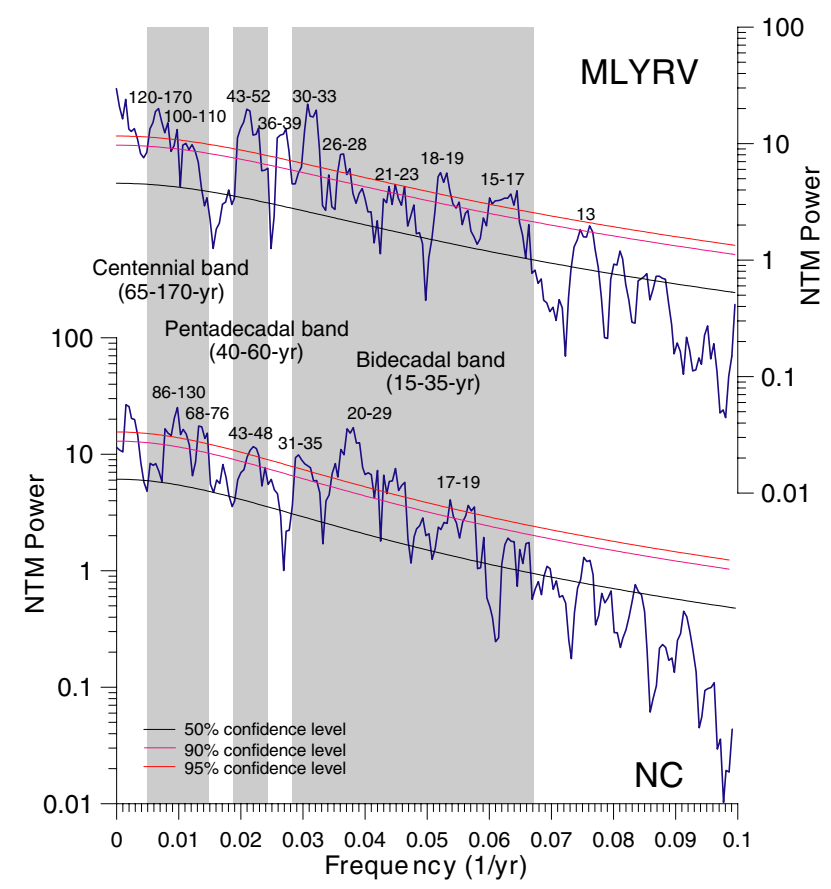

Fig. 4. MTM results of the MLYRV and NC DWI time series. Resolution and taper number used in the MTM analysis are 2 and 3, respectively; red noise null hypothesis is selected; a robust estimate of the red noise background is calculated using the approach of Mann and Lee (1996), and its confidence levels are shown.

ation. We conducted coherency analysis on two time series from NC and MLYRV. The result shows that coherent spectral peaks significant at $95 \%$ or $90 \%$ confidence level include 15-yr, 19-yr, 25-yr, 33-34-yr, 47-50-yr, 68-yr, and 149-yr. These coherent spectral peaks only cover parts of individual peaks revealed by the MTM, so we combine those individual peaks into three relatively broad bands, i.e. bidecadal (15$35-\mathrm{yr})$, pentadacadal (40-60-yr), and centennial (65-170-yr) bands based on the result of coherency analysis and MTM to elucidate their temporal evolution.

We employed wavelet approach to determine the temporal evolution of dominant oscillation bands. Bidecadal, pentadacadal, and centennial bands explain 36.3\% (39.1\%), 17.8\% (17.4\%), and $21.3 \%$ (24\%) of variance of the MLYRV (NC) time series. The amplitudes of these bands were not constant through time and they varied substantially from one period to another over the past 1500 years (Fig. 4c-e). Six intervals are distinguished by the temporal evolution in the amplitude of these bands. The strongest signal of centennial oscillation occurred before AD 800 in both NC and the MLYRV. The variation in the MLYRV was in good phase coherence with that in NC. The pentadecadal oscillation mode was weak in the MLYRV, whereas it was relatively strong in NC from AD 500 to 800 . During this period, the bidecadal oscillation in the MLYRV time series was weak in its early half and strong in its late half. Conversely, it was strong in NC time series 
from $\mathrm{AD} 500$ to 700, and weak from $\mathrm{AD} 700$ to 800 . The amplitude of the centennial oscillation in both time series gradually decreased and reached their minima during the period from $\mathrm{AD} 800$ to 1130 . On the other hand, the phase relation of the centennial oscillation between two regions changed from "in-phase" to "out-of-phase" at the end of this period. During this period, the pentadecadal oscillation over NC and the MLYRV changed from weak to strong in a way opposite to that of the centennial oscillation. The bidecadal oscillation was strong in AD 900-1000 and AD 1060-1130, and it was weak in the other intervals of this period. The period of $\mathrm{AD}$ $1130-1400$ is characterized by strong centennial mode and weak pentadecadal oscillation. The amplitude of bidecadal oscillation over the MLYRV was strong, whereas it was relatively weak over NC during this period. The strongest pentadecadal oscillation over NC and the MLYRV occurred in the period from AD 1400 to 1700 , when the centennial oscillation was still as strong as in the previous period. During this period, the bidecadal oscillation was relatively strong over the MLYRV, whereas its power reached the maxima over NC. The variation of centennial and pentadecadal oscillations decreased in the interval from AD 1700 to 1900, when the bidecadal oscillation maintained strong. The 20th century is distinguished from preceding interval by weak centennial and bidecadal oscillations and strong pentadecadal oscillation.

After analyzing DWI data of AD 1470-1950 and observed summer rainfall of 1951-1999 from individual station over eastern China (25 stations), Zhu and Wang (2002) found an 80 -yr oscillation with the $95 \%$ confidence level in some areas. This oscillation over $\mathrm{NC}$ was out of phase to that along the MLYRV during the past 530 years. Our results derived from spectral analysis and wavelet filtering suggested the occurrence of this centennial oscillation from a regional precipitation view. However, the phase relationship between NC and the MLYRV was not constant during the past 1500 years. "Out-of-phase" as indicated by Zhu and Wang (2002) and "in-phase" were found after and before AD 1100. This phenomenon probably suggests a major shift of climate around AD 1100 over China. Some previous studies (e.g. Wang and Zhang, 1996) indicated that the largest shift of climate in both precipitation and temperature during the last two millennia in China occurred around AD 1230. It seems reasonable to speculate that this transition in the phase relationship of centennial oscillation between NC and the MLYRV could have been caused by a major shift of climate over China in 12th or 13th century. A comparison of reconstructed temperature from multi-proxy data in China (Yang et al., 2004) with our results further supports our speculation. The warm period ended around AD 1100 in China. This comparison also reveals an interesting fact that dominant long-term oscillation modes varied during the last 1500 years under different temperature conditions. During the warm periods such as the Medieval Warm Period (AD 800-1100 in China, Yang et al., 2002) and 20th century, the centennial oscilla- tion was weak and the pentadecadal oscillation was strong. During the cold periods such as AD 500-800 and AD 14001700 , both the centennial and pentadecadal oscillations were strong, although the pentadecadal oscillation in the MLYRV was not as strong as that in NC during the former cold period. During the normal conditions such as periods of $\mathrm{AD}$ 1100-1400 and AD 1700-1900, the centennial oscillation was relatively strong whereas pentadecadal oscillation was very weak. The correlation of temperature conditions with the bidecadal oscillation is not as clear as that with the centennial and pentadecadal oscillations, although strong signals of the bidecadal oscillation more frequently occurred in cold or normal conditions.

\subsection{Variability of summer precipitation in modeled data}

Here we present the results of millennium simulations using CCSM2.0.1. Three experiments including an AD 1000 control run, a run with orbital forcing and solar forcing, and another run with full forcing, were carried out in this study. In the $\mathrm{AD} 1000$ control run, the model was first run fully coupled for 300 years in a spin up mode with constant 1990 conditions. The run was then continued from year 300 without any forcing changes (fixed at AD 1000 forcing conditions, i.e. solar forcing is $1365.0 \mathrm{~W} \mathrm{~m}^{-2}$, the concentration of $\mathrm{CO}_{2}, \mathrm{CH}_{4}, \mathrm{~N}_{2} \mathrm{O}$, CFC-11, and CFC-12 are 280, 680, 266, 0, and $0 \mathrm{ppbv}$, respectively) and was run fully coupled for 1000 years. The forced simulations were started from fully coupled 300 years. The analysis of the global mean sea surface temperature from the control run show a small drift, suggesting that the spin up procedure is adequate to avoid long-term drift of climate. The orbital parameter is almost constant during the last 1000 years; it is thus neglected in our interpretations of model data.

Figure 5 shows the spatial patterns of summer precipitation over East Asia $\left(10-50^{\circ} \mathrm{N}, 90-130^{\circ} \mathrm{E}\right)$ in observed and simulated data from 1950 to 1995 . Generally, CCSM2.0.1 underestimates the summer precipitation in the regions south to $30^{\circ} \mathrm{N}$, whereas it overestimates in the regions north to $30^{\circ} \mathrm{N}$, especially the Sichuan Basin. This might be an indication that CCSM2.0.1's performance in simulating the effect of the Tibetan Plateau on precipitation needs to be improved. However, the spatial pattern of summer precipitation in the regions beyond the Tibetan Plateau, such as eastern China, is better simulated in the three experiments, although the summer precipitation is obviously underestimated in the southeastern costal region. Nevertheless, the summer precipitation is well simulated in our study regions, the MLYRV and NC, where a zonal gradient of summer precipitation similar to observed pattern exhibits significantly in the three experiments. Figure 6a shows a comparison of distribution statistics (full range, 25th, 50th, 75th quartiles and the mean) in observed and modeled summer precipitation from 1951 to 1995 in the MLYRV and NC. The simulated means and medians of summer precipitation in three experiments are rather stable and 
they are close to the observed ones in the MLYRV. The dispersion ranges of simulated summer precipitation for this period in the MLYRV are also comparable to that from observation. The simulated means and medians in NC are about 20$30 \mathrm{~mm}$ higher than observed ones. The dispersion range for $\mathrm{NC}$ in the experiment with full forcing is smaller than other two experiments and it is close to the observed one. Although the difference in modeled summer precipitation between the two regions is not as distinct as observed one, one-sample Ttest indicates that the means of summer precipitation in the two regions are significantly different at the $99 \%$ confidence level, suggesting that these two regions apparently belong to different regimes of summer precipitation as indicated by observed data. The simulated and observed annual precipitation (Fig. 6b) and temperature (not shown here) variations also show this fact. In the MLYRV, the monthly precipitation peak occurs in May and June, whereas NC experiences the highest monthly precipitation in July and August. Therefore, it seems reasonable to use these modeled data in these two regions to determine the variability of summer precipitation in millennium simulations and then to further compare with proxy data.

Figure 7 shows time series of simulated summer precipitation in the MLYRV and NC during the last millennium. 10-yr moving averages are taken for three purposes, i.e. maximizing the signal-to-noise ratio, emphasizing the decadal to centennial variability, and maintaining a consistence with proxy data for a model-data comparison. The general impression from the figure is that the difference of simulated summer precipitation is relatively large among three experiments and the summer precipitation varies in an apparent periodic manner. This large difference is not unexpected since the control run with fixed forcing only reproduces the internal variability of summer precipitation and the other two runs driven by solar forcing and full forcing probably capture both internal and external variability. The model-data comparison for the MLYRV and NC indicates that the full forcing run produces the temporal pattern similar most to that observed in proxy data. We note that the temporal pattern in full forcing run matches that in the solar forcing run and proxy data well in its the early 320 year (AD 1000-1320), when correlation coefficients calculated from 101-yr sliding window show significant positive correlation among them. This is presumably due to inactive volcanic activities during in this period. The peaks and valleys in these time series do not parallel well between model and proxy data from AD 1320 to 1900 . Both positive and negative correlations occur in this period. The difference in temporal patterns between two runs of solar forcing and full forcing becomes larger. The poor matches between model and proxy data as well as different runs occur in the last century, when no significant correlation or negative correlation is observed. Therefore, it seems reasonable to speculate that different combinations of forcing conditions would modulate the variability in summer precipitation during the different periods.
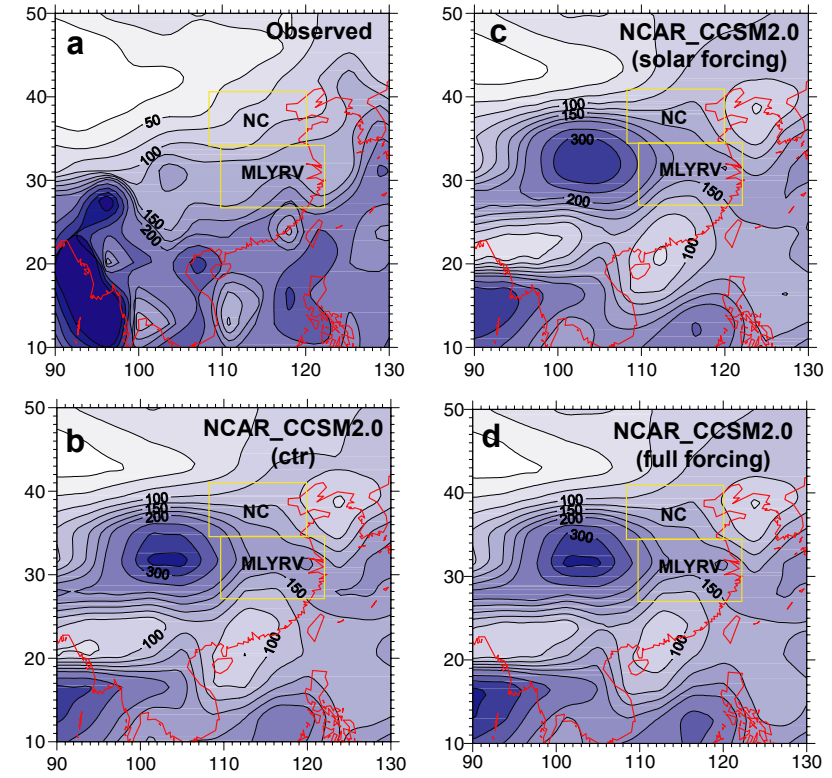

Fig. 5. Spatial patterns of summer precipitation (unit: $\mathrm{mm} / \mathrm{month}$ ) in observed data (a), and modeled data of three experiments, i.e. control run (b), orbital and solar forcing driven run (c), and full forcing driven run (d). All data are 45-yr averages of 1951-1995.

Proxy data of summer precipitation exhibits some significant decadal to centennial oscillations during the last 1500 years. To examine possible attributions of these oscillations, we also conduct MTM analysis on the modeled summer precipitation from three runs. As shown by Fig. 8, only decadal to multidecadal periodicities are well presented for the MLYRV and NC in the control run. The most prominent oscillation mode for both regions is the pentadecadal (4060 -yr) periodicity, which is significant at the $95 \%$ confidence level. Other significant oscillation modes for the MLYRV include 15-18-yr, 21-25-yr, and 27-37-yr cycles. The latter two cycles are also found in NC. No significant centennial band (65-170-yr) oscillation shows up in the control run. In the solar forcing run, the dominant oscillations with the $95 \%$ confidence level in the MLYRV are 16-17-yr, 22-yr, 27-35, and 105-170-yr periodicities, whereas they are 17-yr, 25-29yr, 30-yr, 37-41-yr, 68-90-yr, and 170-260-yr cycles in NC. Additionally, there are two cycles at 50-60-yr and 65-80-yr significant at the $90 \%$ confidence level in the MLYRV. In the full forcing run, the major oscillation modes for the MLYRV are 17-21-yr, 22-25-yr, and 37-41-yr variations, which are significant at the $95 \%$ confidence level. A 50-72-yr cycle with the $90 \%$ confidence level is also seen in the MLYRV. In NC, significant oscillation modes include 19-21-yr, 23$27-y r, 29-y r$, and 56-80-yr periodicities. Theses modes are significant at the $95 \%$ confidence level.

As mentioned above, three dominant cyclic modes revealed by proxy data are bidecadal band (15-35-yr), pentadecadal band (40-60-yr), and centennial band (65-170-yr) 

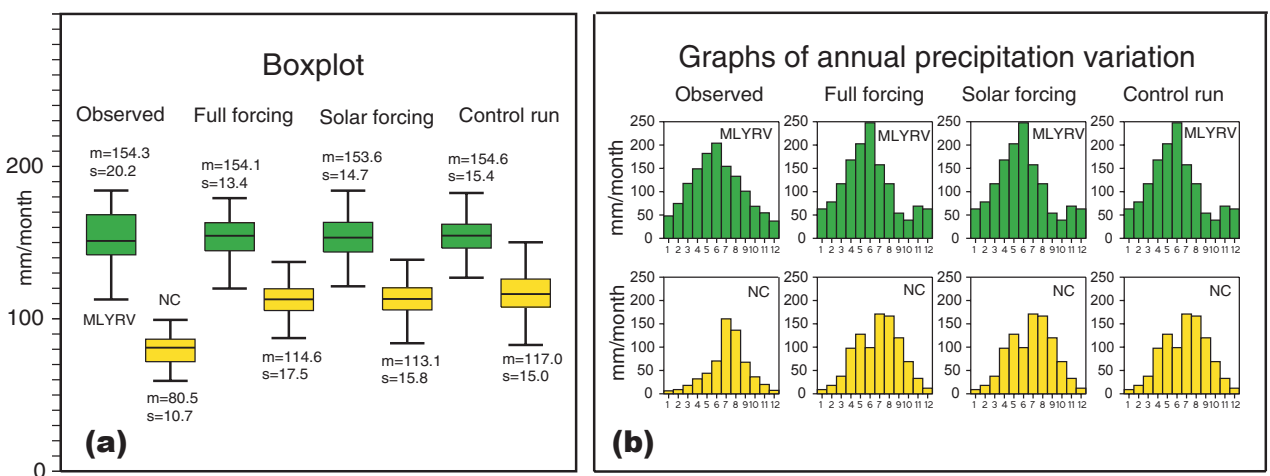

Fig. 6. (a) Boxplots summarizing the distribution statistics of observed and modeled summer precipitation (May-September) from 1951 to 1995. In each boxplot the box extends from the lower (first) to the upper (third) quartile, with the line inside the box denoting the median. Lines indicating the tails extend outward from the quartiles to the minimum/maximum value. The mean values and standard deviations are also shown. (b) Graphs of observed and modeled annual precipitation variations based on the monthly mean precipitation from 1951 to 1995 .

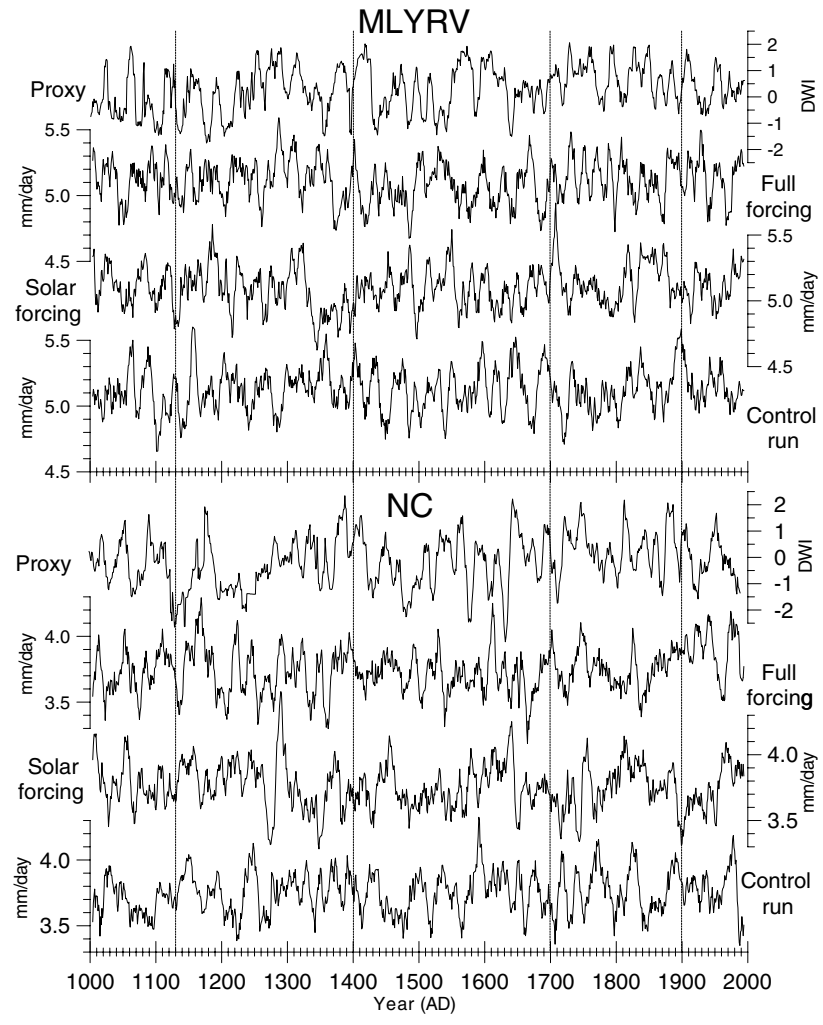

Fig. 7. A comparison of summer precipitation from proxy data and modeled data in the MLYRV and NC. All data are 10-yr moving averages. The dot lines represent the period boundaries recognized by temporal evolutions of decadal to centennial oscillations in Sect. 3.2.

oscillations. Centennial band oscillation is not found in the control run, indicating that it is not an internal variability. This oscillation is clearly visible in the solar forcing run, however, the full forcing run does not produce significant centennial peaks as well as the solar forcing run. The possible reason why the centennial peak becomes insignificant in the full forcing run is that the change amplitude of solar forcing is smaller than that of other forings such as volcanic forcing, the response of summer precipitation to solar forcing may be overwhelmed by other forcings. On the other hand, peaks in the centennial band oscillation revealed by proxy do not match those in the two simulations with solar forcing and full forcing. Therefore, whether this centennial oscillation is linked to century-type periodicity in solar forcing as suggested by some previous studies (e.g. Zhu and Wang, 2002) is still an open question.

Another dominant oscillation registered in proxy data is the pentadecadal oscillation (40-60-yr). This oscillation is not significant in short observation records (1951-2004 and 1880-2002; Ding et al., 2007). The predominant oscillation mode in observation records is bidedacadal or 30-40-yr periodicity (Li et al., 2004; Ding et al., 2007). It is interesting to note that this oscillation clearly stands up in the control run with the $99 \%$ confidence level. This might be an indication that this oscillation is an internal fluctuation of the climate system. It has been suggested that the multidecadal variation of summer precipitation over eastern China is associated with the internal process of the ocean-atmosphere, such as ENSO events and PDO (Li et al., 2005; Zhou et al., 2006). Several studies have characterized the PDO as emerging from a phase-locked interaction between oscillations with ca. 20 and 50-yr periods, and regime shifts occur when the oscillations change phase simultaneously (Nakamura et al., 1997; Minobe, 1999, 2000). The amplitude of the pentadecadal variation, an oscillation providing the basic regime timescale of PDO is not constant through time as indicated by Fig. 3 and some previous studies (e.g. Shen et al., 2006). Therefore, this oscillation is likely an internal variability of the ocean-atmosphere system and its length and amplitude might be modulated by external forcing or other internal processes. 
Schlesinger and Ramankutty (1994) found that there is a 6570 -yr oscillation in temperature of Northern Hemisphere and it is the statistical result of 50-88-yr oscillations. Comparing observations with model simulations, they suggested that this oscillation arises from the internal variability of the oceanatmosphere system. Using a fully coupled ocean-atmosphere model, Delworth et al. (1993) showed a climatic oscillation with a time scale of approximately 50 years produced by the ocean-atmosphere interaction. Goswami (2006) noted a quasi 50-60-yr interdecadal fluctuation in interannual variability of the south Asian summer monsoon, the east Asian summer monsoon, and the ENSO. He hypothesized that this oscillation of the Asian monsoon and ENSO is a manifestation of a global coupled ocean-atmosphere mode of oscillation. These findings support our interpretation of this pentadecadal oscillation observed in both model and proxy data as an internal variability of the ocean-atmosphere system.

The bidecadal band oscillation (15-35-yr) in proxy data consists of a series of oscillation modes. Dominant modes include 15-19-yr, 21-29-yr and 3-1-35-yr periodicities. These oscillation modes can be found in both control run and forced runs. Thus it is difficult to determine whether it is an internal or external variability. Previous studies suggested that the decadal-interdecadal oscillations within bidecadal band found in the Pacific sea-surface temperature, ENSO events, and PDO are largely internal, resulting from the oceanatmosphere interaction and the tropical-extratropical interaction (Zhang et al., 1997; Nakamura et al., 1997; Minobe, 1999; Evans et al., 2001; Liu et al., 2002; Deser et al., 2004; Schneider and Cornuelle, 2005; Nonaka et al., 2006). Therefore, the bidecadal band oscillation in our proxy and model data is likely an internal variability.

\subsection{Variability in spatial pattern of summer precipita- tion in proxy and modeled data}

As mentioned in the introduction, some studies using relatively short observed data (several decades to one century) indicated an increase in the frequency of drought-innorth/flood-in-south over eastern China during the last few decades (Xu, 2001; Ding et al., 2007). It is evident that records longer than multi-decade are necessary to examine whether this conclusion is solid in the millennium or multi-century context of climate. Here we use both proxy and model data to examine the dominant spatial patterns of anomalous summer precipitation events over eastern China and to determine how unusual this spatial pattern of summer precipitation recorded in the last few decades. The annuallyresolved proxy data of summer precipitation used here is the area-weighted regional DWI developed from the network of DWI over eastern China (Shen et al., 2008). It covers the last 530 years. Model data is from the full forcing run. Both data are standardized using the means and standard deviations of 1951-1995.

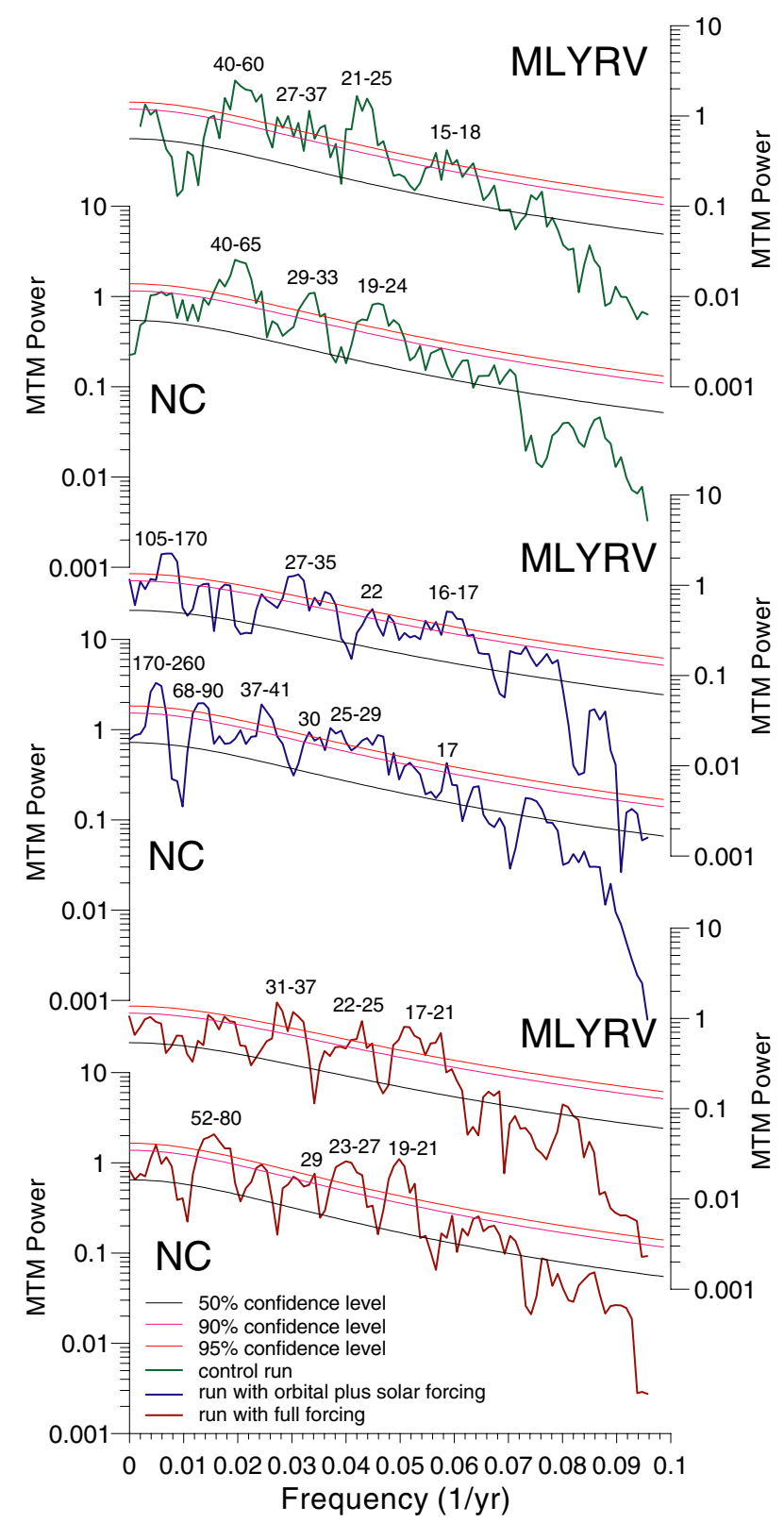

Fig. 8. MTM results of summer precipitation in three experiments of millennium simulation. Resolution and taper number used in the MTM analysis are 2 and 3, respectively; red noise null hypothesis is selected; a robust estimate of the red noise background is calculated using the approach of Mann and Lee (1996), and its confidence levels are shown.

Figure 9 is 4-quarter plot of proxy and model data showing the spatial patterns of summer precipitation in the MLYRV and NC. We use one standard deviation as the criterion to define an anomalous summer precipitation event. When the standardized DWI values in two regions are within the range of one standard deviation, this year witnesses a normal summer in precipitation. As the standardized DWI value in any 

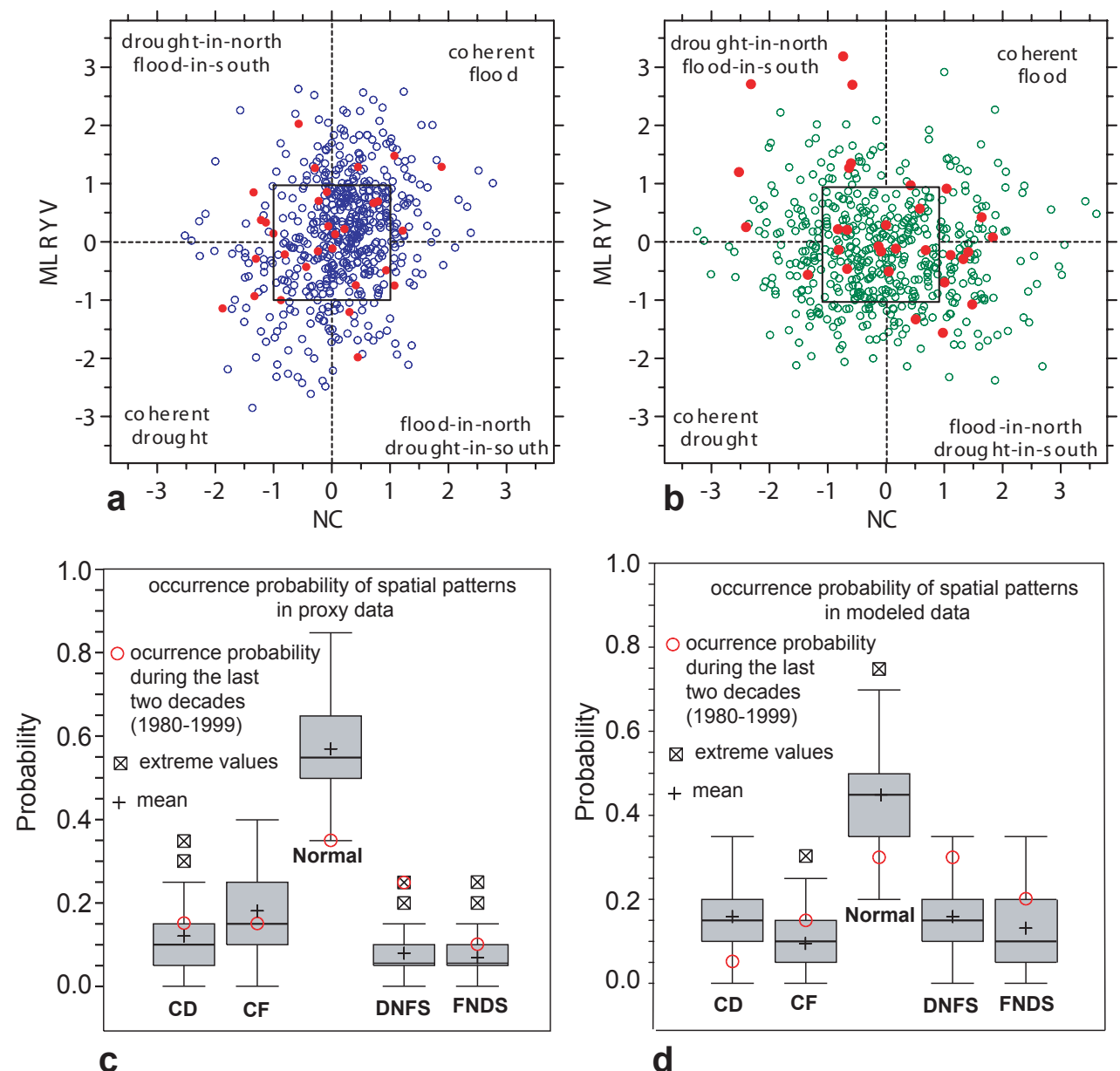

Fig. 9. Four-quarter plots of standardized proxy data (DWI) (a) and modeled data (experiment with full forcing) (b) of summer precipitation during AD 1470-1999 over the MLYRV and NC showing the spatial pattern of anomalous summer precipitation events. The last 30 years (1970-1999) are presented by red dots. The proxy and modeled data are standardized using their means and standard deviations of 19511995. Boxplots show the probability distributions of different spatial patterns of anomalous summer precipitation events revealed by proxy (c) and modeled (d) data. The shaded box around the median represents the inner quartile range (IQR), which identifies the region between the 25th and 75th percentiles. The whiskers extending from the IQR represent the largest/smallest value that is still within the median \pm 1.5 (IQR). Any value beyond the whiskers is subjectively considered to be an extreme value or an outlier.

region is beyond the range of one standard deviation, this year is defined as an anomalous summer precipitation event. Its spatial pattern is then assigned through comparing the standardized DWI values in the two regions. Two modes, coherence and dipole consisting four spatial patterns, are then defined. Coherence mode includes coherent drought and coherent flood, whereas the dipole mode includes droughtin-north/flood-in-south and flood-in-north/drought-in-south. After this procedure, we use a moving $20-\mathrm{yr}$ window to calculate the occurrence probability of four spatial patterns of anomalous summer precipitation events and normal conditions.

The distribution statistics of their occurrence probability in 530-yr proxy and model data is shown in the lower panel of Fig. 9. As expected, normal conditions have the highest occurrence probability in both proxy and model data. For proxy data, the most frequent anomalous summer precipitation event was coherent flood with a mean of 0.18 during the past 530 years. The second one was coherent drought with a mean of 0.1 . Two spatial patterns of dipole mode occurred less frequently than the spatial patterns of coherence mode. There are some extreme values in the occurrence probability of coherent drought, and two dipole patterns in proxy data. These extreme values indicate some time intervals with extremely high occurrence probability of these spatial patterns. Proxy data indicate that the periods with extremely high probability ( 0.35 or 0.30 ) of coherence drought were AD 1481-1490 and 1927-1942. The high frequency of drought-in-north/flood-in-south occurred in AD 1555-1565, 1601-1610, and 1980-2000 (with probability of more than 
$0.25)$. The flood-in-north/drought-in-south was the most frequent anomalous summer precipitation event in AD 16451654 and 1955-1964. For the last two decades, the occurrence probabilities of coherent drought, coherent flood, and flood-in-north/drought-in-south are close to their means of the last 530 years. The probability of normal conditions is markedly lower than its means, close to a statistically significant level, indicating that anomalous summer precipitation events happened more frequently in recent two decades. The probability value of drought-in-north/flood-in-south occurs as an outlier, i.e. this value is significantly different from its mean of the last 530 years at the $99 \%$ confidence level. It means that this variability in spatial pattern of summer precipitation during the last two decades is unusual even in the five-century context. Model data seems to support observed result, although there is somewhat difference in the probability distribution of normal conditions and four spatial patterns of anomalous summer precipitation events. For the last two decades, a decrease in the occurrence probability of normal conditions and an increase in the probability of drought-innorth/flood-in-south can be seen, although statistically they are not significantly different from their means.

\section{Concluding remarks}

This study analyzes observational, proxy, and model data to investigate the variability of summer precipitation over eastern China during the last millennium with a focus on the middle and lower Yangtze River Valley and North China. On the interannual scale, 2-3-yr cycle, typical TBO and ENSO signals are well presented in observational data over the MLYRV and NC. Oscillations on the decadal scale are not as distinct as these on the interannual scale in the instrumental times. Spectral analysis of regional proxy data of summer precipitation reveals three statistically significant oscillation bands, i.e. bidecadal (15-35-yr), pendadecadal (40$60-y r)$, and centennial (65-170-yr) band during the past 1500 years. The time evolutions of these bands revealed by the wavelet filtering indicate that the amplitudes of these oscillation bands are not constant through time. They vary substantially from one period to another over the past 1500 years. A comparison of the behaviors of these oscillation bands with temperature conditions in China shows that these periods distinguished by the temporal evolutions of oscillations corresponds those episodes with different temperature conditions. Weak centennial oscillation and strong pentadecadal oscillation occurred in warm conditions during the MWM and 20th century. During the cold periods of AD 500-800 and AD 1400-1700, both the centennial and pentadecadal oscillations were strong. When the temperature was in relatively normal conditions, pentadecadal oscillation was very weak while the centennial oscillation was relatively strong. Our analyses also show that the phase relationship in centennial oscillation between NC and the MLYRV was not constant during the past 1500 years. It changed from "in-phase" to "out-of-phase" at about AD 1100. It may suggest a major shift of climate in China around AD 1100.

A comparison of observational data with modeled data from millennium simulations using CCSM2.0.1 shows that the model reproduces the tempo-spatial patterns of summer precipitation over East Asia in broad terms. A model/data intercomparison suggests that the pentadecadal and bidecadal oscillations could be associated with internal variability of climate system. However, further analyses on the model results such as ocean and land temperature, atmospheric circulations, and moisture transportation are needed to separate the factors governing these oscillations and better understand underlying mechanisms.

In this study, we also analyze the occurrence probability of spatial patterns of anomalous summer precipitation events using proxy and model data. Our analyses on both model and proxy data demonstrate that an increase in the frequency of drought-in-north/flood-in-south over eastern China during the last two decades is unusual in the past five centuries. The study of Menon et al. (2002) suggested that this trend might be related to increased black carbon aerosols.

Acknowledgements. This work is supported by a grant from the Office of Biological and Environmental Sciences, Office of Sciences, US Department of Energy (DOE) to SUNY-Albany. It is also supported by the climate change special fund of China Meteorological Administration (grant \# CCSF-2006-11-1) and the project for Young Scientists' Fund of the National Natural Science Foundation of China (grant \# 40701021).

Edited by: Z. Guo

\section{References}

Allen, M. R. and Ingram, W. J.: Constraints of future changes in climate and the hydrologic cycle, Nature, 419, 224-231, 2003.

Ammann, C. M., Joos, F., Schimel, D. S., Otto-Bliesner, B. L., and Tomas, R. A.: Solar influence on climate during the past millennium: results from transient simulations with the NCAR Climate System Model, Proc. Natl. Acad. Sci. USA, 104, 3713-3718, 2007.

Barnnet, T. P., Hasselmann, K., Chelliah, M., Delworth, T., Hegerl, G., Jones, P., Rasmussen, E., Roeckner, E., Ropelewski, C., Santer, B., and Tett, S.: Detection and attribution of climate change: A status report, B. Am. Meteor. Soc., 12, 2631-2659, 1999.

Bauer, E., Claussen, M., Brovkin, V., and Huenerbein, A.: Assessing climate forcing of the Earth system for the past millennium, Geophys. Res. Lett., 30, 1276, doi:10.1029/2002GL016639, 2003.

Bradley, R. S., Briffa, K. R., Cole, J., Hughes, M. K., and Osborn, T. J.: The climate of the last millennium, in: Paleoclimate, Global Change and the Future, edited by: Alverson, K., Bradley, R. S., and Pedersen, T. F., Springer-Verlag, Berlin, 105-141, 2003.

Chang, C. P., Zhang, Y., and Li, T.: Interanual and interdecadal variation of the East Asian summer monsoon rainfall and tropical 
SSTs: Part 1, Roles of the Subtropical Ridge, J. Clim., 13, 43104325, 2000.

Clemens, S. C., Wang, P., and Prell, W. L.: Asian monsoons and global linkages on milankovitch and sub-milankovitch time scales, Mar. Geol., 201, 1-250, 2003.

CNMA (Chinese National Meteorological Administration): Yearly Charts of Dryness/wetness in China for the Last 500-year Period, Chinese Cartographic Publishing House, Beijing, 1981.

Crowley, T. J.: Causes of climate change over the past 1000 years, Science, 289, 270-277, 2000.

Delworth, T., Manbe, M., and Stouffer, R. J.: Interdecadal variations of the thermohaline circulation in a coupled oceanatmosphere model, J. Clim., 6, 1993-2011, 1993.

Deser, C., Phillips, A. S., and Hurrell, J. W.: Pacific interdecadal climate variability: linkages between the tropics and the North Pacific during boreal winter since 1900, J. Clim., 17, 3109-3124, 2004.

Ding, Y., Wang, Z., and Sun, Y.: Inter-decadal variation of the summer precipitation in East China and its association with decreasing Asian summer monsoon, Int. J. Climatol., 28, 1139-1161, doi:10.1002/joc.1615, 2007.

Ding, Y.: Monsoons over China, Kluwer Academic Publishers, Dordrecht, 419 pp., 1991.

Evans, M. N., Cane, M. A., Schrag, D. P., Kaplan, A., Linsley, B. K., Villalba, R., and Wellington, G. M.: Support for tropicallydriven Pacific decadal variability based on paleoproxy evidence, Geophys. Res. Lett., 28, 3689-3692, 2001.

Feddema, J. J., Oleson, K. W., Bonan, G. B., Mearns, L. O., Buja, L. E., Meehl, G. A., and Washington, W. M.: The importance of land-cover change in simulating future climates, Science, 310, 1674-1678, 2005.

Folland, C. K., Karl, T. R., Christy, J. R., Clarke, R. A., Gruza, G. V., Jouzel, J., Mann, M. E., Oerlemans, J., Salinger, M. J., and Wang, S.-W.: Observed Climate Variability and Change, in: Climate Change 2001: The scientific basis. Contribution of Working Group I to the Third Assessment Report of the Intergovernmental Panel on Climate Change, edited by: Houghton, J. T., Ding, Y., Griggs, D. J., Noguer, M., Van der Linden, P. J., Dai, X., Maskell, K., and Johnson, C. A., Cambridge University Press, Cambridge, UK, 99-181, 2001.

Fu, C.: impacts of human-induced land cover change on East Asia monsoon, Global and Planetary Change, 37, 219-229, 2003.

Ghil, M., Allen, M. R., Dettinger, M. D., Ide, K., Kondrashov, D., Mann, M. E., Robertson, A. W., Saunders, A., Tian, Y., Varadi, F., and Yiou, P.: Advanced spectral methods for climatic time series, Rev. Geophys., 40, 3.1-3.41, doi:10.1029/2000RG000092, 2002.

Giorgi, F.: Climate change prediction, Climatic Change, 73, 239265, 2005.

Goswami, B. N.: The Asian monsoon: interdecadal variability, in: The Asian Monsoon, edited by: Wang, B., Springer-Verlag, Berlin, 295-326, 2006

Gupta, A. K., Das, M., and Anderson, D. M.: Solar influence on the Indian summer monsoon during the Holocene, Geophys. Res. Lett., 33, L17703, doi:10.1029/2005GL022685, 2005.

Hegerl, G. C., Zwiers, F. W., Braconnot, P., Gillett, N. P., Luo, Y., Marengo Orsini, J. A., Nicholls, N., Penner, J. E., and Stott, P. A.: Understanding and Attributing Climate Change, in: Climate Change 2007: The Physical Science Basis. Contribution of
Working Group I to the Fourth Assessment Report of the Intergovernmental Panel on Climate Change, edited by: Solomon, S., Qin, D., Manning, M., Chen, Z., Marquis, M., Averyt, K. B., Tignor, M., and Miller, H. L., Cambridge University Press, Cambridge, UK, 663-746, 2007.

Hulme, M.: A 1951-1980 global land precipitation climatology for the evaluation of general circulation models, Clim. Dynam., 7, 57-72, 1992.

Hulme, M.: Global changes in precipitation in the instrumental period. In: Global Precipitation and Climate Change, edited by: Desbois, M. and Désalmand, F., Springer-Verlag, 387-405, 1994.

Jones, P. D. and Mann, M. E.: Climate over past millennia, Rev. Geophys., 42, 1-42, 2004.

Jones, P. D., Osborn, T. J., and Briffa, K. R.: The evolution of climate over the last millennium, Science, 292, 662-667, 2001.

Kiehl, J. T. and Gent, P. R.: The Community Climate System Model, version 2, J. Clim., 17, 3666-3682, 2004.

Lau, K.-M. and Wu, H. T.: Principal modes of rainfall - SST variability of the Asian summer monsoon: a reassessment of the monsoon - ENSO relationship, J. Clim., 14, 2880-2895, 2001.

Li, C., He, J., and Zhu, J.: A review of decadal/interdecadal climate variation studies in China, Adv. Atmos. Sci., 21, 425-436, 2004.

Li, Q., Yang, S., Kousky, V. E., Higgins, R. W., Lau, K. M., and Xie, P.: Features of cross-Pacific climate shown in the variability of China and US precipitation, Int. J. Climatol., 25, 1675-1696, 2005.

Liu, Z., Wu, L., Gallimore, R., and Jacob, R.: Search for the origins of Pacific decadal climate variability, Geophys. Res. Lett., 29, 1404, doi:10.1029/2001GL013735, 2002.

Mann M. E. and Lees, J. M.: Robust estimation of background noise and signal detection in climatic time series, Clim. Change, 33 , 409-445, 1996.

Menon, S., Hansen, J., Nazarenko, L., and Luo, Y.: Climate Effects of Black Carbon Aerosols in China and India, Science, 297, 2250-2253, 2002.

Minobe, S.: Resonance in bidecadal and pentadecadal climate oscillations over the North Pacific: Role in climatic regime shifts, Geophys. Res. Lett., 26, 855-858, 1999.

Minobe, S.: Spatio-temporal structure of the pentadecadal variability over the North Pacific, Prog. Oceanogr., 47, 381-408, 2000.

Nakamura, H., Lin, G., and Yamagata, T.: Decadal climate variability in the North Pacific during the recent decades, Bull. Am. Meteorol. Soc., 78, 2215-2225, 1997.

Nonaka, M., Nakamura, H., Tanimoto, Y., Kagimoto, T., and Sasaki, H.: Decadal variability in the Kurishio-Oyashio extension simulated by an eddy-resolving OGCM, J. Clim., 19, 19701989, 2006.

Pielke Sr., R. A., Adegoke, J., Beltra-Przekurat, A., Hiemstra, C. A., Lin, J., Nair, U. S., Diyogi, D., and Nobis, T. T.: An overview of regional land-use and land-cover impacts on rainfall, Tellus, 59B, 587-601, 2007.

Samel, A. N., Wang, W.-C., and Liang, X. Z.: The Monsoon rainband over China and relationships with the Eurasian circulation, J. Clim., 12, 115-131, 1999.

Schlesinger, M. E. and Ramankutty, N.: An oscillation in the global climate system of period 65-70 years, Nature, 367, 723-726, 1994.

Schneider, N. and Cornuelle, B. D.: The forcing of the Pacific 
decadal oscillation, J. Clim., 18, 4355-4373, 2005.

Shen, C., Wang, W.-C., Hao, Z., and Gong, W.: Characteristics of Anomalous Precipitation Events over Eastern China during the Past Five Centuries, Clim. Dynam., 31, 463-476, 2008.

Shen, C., Wang, W.-C., Gong, W., and Hao, Z.: A Pacific decadal oscillation record since $1470 \mathrm{AD}$ reconstructed from proxy data of summer rainfall over eastern China, Geophys. Res. Lett., 33, L03702, doi:10.1029/2005GL024804, 2006.

Shen, S. and Lau, K. M.: Biennial oscillation associated with the east Asian monsoon and tropical sea surface temperatures, J. Meteorol. Soc. Japan, 73, 105-124, 1995.

Stocker, T. F., Clarke, G. K. C., Le Treut, H., Lindzen, R. S., Meleshko, V. P., Mugara, R. K., Palmer, T. N., Pierrehumbert, R. T., Sellers, P. J., Trenberth, K. E., and Willebrand, J.: physical Climate Processes and Feedbacks, in: Climate Change 2001: The scientific basis. Contribution of Working Group I to the Third Assessment Report of the Intergovernmental Panel on Climate Change, edited by: Houghton, J. T., Ding, Y., Griggs, D. J., Noguer, M., Van der Linden, P. J., Dai, X., Maskell, K., and Johnson, C. A., Cambridge University Press, Cambridge, UK, 417-470, 2001.

Torrence, C. and Compo, G. P.: A practical guide to wavelet analysis, B. Am. Meteor. Soc., 79, 61-78, 1998.

Waliser, D. E.: Intraseasonal variability, in: The Asian Monsoon, edited by: Wang, B., Springer-Verlag, Berlin, 203-257, 2006.

Wang, B.: The Asian monsoon. Springer-Verlag, Berlin, 787 pp., 2006.

Wang, B., Wu, R., and Fu, X.: Pacific-East Asian teleconnection: how does ENSO affect East Asian climate?, J. Clim., 13, 15171536, 2000.

Wang, B., Wu, R., and Li, T.: atmosphere-warm ocean interaction and it impacts on the Asian-Australian monsoon variation, J. Clim., 16, 1195-1211, 2003.

Wang, J. and Zhang, P.: Abrupt change of climate in Chinese historical times. In: Historical climate change in China, edited by: Shi, Y. and Zhang, P., Shandong Science and Technology Press, Jinan, 464-467, 1996.

Wang, P., Clemens, S., Beaufort, L., Braconnot, P., Ganssen, G., Jian, Z., Kershaw, P., and Sarnthein, M.: Evolution and variability of the Asian monsoon system: state of the art and outstanding issues, Quat. Sci. Rev., 24, 595-629, 2005.
Wang, Y., Cheng, H., Edwards, R. L., He, Y., Kong, X., An, Z., Wu, J., Kelly, M. J., Dykoski, C. A., and Li, X.: The Holocene Asian monsoon: Links to solar changes and North Atlantic climate, Science, 308, 854-857, 2005.

Webster, P. J., Magana, V. O., Palmer, T. N., Shukla, J., Tomas, R. A., Yanai, M., and Yasunari, T.: Monsoons: processes, predictability, and the prospects for prediction, J. Geophys. Res., 14, 14451-14510, 1998.

Wu, T. and Qian, Z:: The relation between the Tibetan winter snow and the Asian summer monsoon and rainfall: an observational investigation, J. Clim., 16, 2038-2051, 2003.

$\mathrm{Xu}, \mathrm{Q}$.: Abrupt change of the mid-summer climate in central east China by the influence of atmospheric pollution, Atmos. Environ., 35, 5029-5040, 2001.

Yang, B., Braeuning, A., Johnson, K. R., and Shi, Y.: General characteristics of temperature variation in China during the last two millennia, Geophys. Res. Lett., 29, 381-384, 2002.

Yang, S. and Lau, K.-M.: Interannual variability of the Asian monsoon, in: the Asian monsoon, edited by: Wang, B., SpringerVerlag, Berlin, 259-293, 2006.

Yoshimori, M., Raible, C. C., Stocker, T. F., and Renold, M.: On the interpretation of low-latitude hydrological proxy records based on Maunder Minimum AOGCM simulations, Clim. Dynam., 27, 493-513, 2006.

Zhang, D., Li, X., and Liang, Y.: Supplement of Yearly Charts of Dryness/wetness in China for the Last 500-year Period, 19932000, J. Appl. Meteor. Sci., 14, 379-389, 2003.

Zhang, Y., Wallace, J. M., and Battisti, D. S.: ENSO-like interdecadal variability: 1900-1993, J. Clim., 10, 1004-1020, 1997.

Zhao, S., Peng, C., Jiang, H., Tian, D., Lei, X., and Zhou, X.: Land use change in Asia and the ecological consequences, Ecol. Res., 21, 890-896, 2006.

Zheng, J., Wang, W-C., Ge, Q., Man, Z., and Zhang, P.: Precipitation variability and extreme events in eastern China during the past 1500 years, Terr. Atmos. Ocean. Sci., 17, 579-592, 2006.

Zhou, W., Li, C., and Chan, J. C. L.: The interdecadal variations of the summer monsoon rainfall over South China, Meteorol. Atmos. Phys., 93, 165-175, 2006.

Zhu, W. and Wang, S.: $80 \mathrm{yr}$ oscillation of summer rainfall over North China and East Asia summer monsoon, Geophys. Res. Lett., 29, 1672, doi:10.1029/2001GL013997, 2002. 